\title{
Intelligent Co-simulation to Consider Urban Climate in Building Energy Simulation
}

\author{
Adrien Gros ${ }^{1}$, Walter Mazuroski ${ }^{1}$, Nathan Mendes ${ }^{1}$, Ricardo C.L.F Oliveira ${ }^{2}$ \\ ${ }^{1}$ Termical system Laboratory, Pontifical Catholic University of Paraná, Curitiba, Brazil \\ ${ }^{2}$ Electric and Computational Engineering Faculty, State University of Campinas-UNICAMP, \\ Campinas, Brazil
}

\begin{abstract}
The microclimate in urban environments could be very different from those obtained from the weather data commonly employed by current building energy simulation (BES) tools, being potentially a great source of inaccuracy in the building performance assessment. Hence, this paper proposes a solution based on a cosimulation strategy, where the urban microclimatic condition is taken into account by the BES tool using a CFD model. Particularly, the convective heat transfer coefficients and near wall air temperature values are simulated by the CFD model considering the local urban geometry and physical parameters. Following a recently proposed co-simulation strategy, called intelligent cosimulation, the BES-CFD coupling is performed only during a short simulation period, for training an Artificial Neural Network (ANN) model. For the remaining simulation period, the ANN model is employed, keeping a great level of accuracy while reducing drastically the computational time normally required by CFD models. The proposed methodology is applied on a BESTEST like building, within a dense urban environment. The cosimulation is implemented in a Python script, using DOMUS as the BES tool and ANSYS-CFX as the CFD model.
\end{abstract}

\section{Introduction}

Traditionally, Building Energy Simulation (BES) tools use standard meteorological data from local airport to model building energy demand or indoor air temperature. However, for buildings located in towns, these data may not representative of the local microclimate. Actually, the urban morphology, the use of materials with high absorptance and heat capacity, the lack of vegetation and the anthropogenic heat sources can modify substantially the wind and temperature fields in the urban environment (Oke, 1987).

The convective heat transfer coefficient (CHTC) and the Near Wall Air Temperature (NWAT) can be strongly modified by the urban environment, which also impact the building energy demand or the indoor air temperature. However, the CHTC is commonly calculated by correlations that ignore the urban environment while the NWAT values are considered the same of those available in weather data files.

In this context, Computational Fluid Dynamics (CFD) models are frequently used to model the urban climate (Toparlar et al., 2015) or the urban heat island (Wang and
$\mathrm{Li}, 2016)$ enabling to estimate velocity and temperature fields in urban environment taking into account different physical phenomena (Bouyer, Inard, and Musy, 2011). Moreover, CFD models can compute specific values for each building walls (Morille, Lauzet, and Musy, 2015; Merlier et al., 2015). They were also used to build empirical models to compute the CHTC in terms of the wind direction and speed for a specific building shape (Emmel, Abadie, and Mendes, 2007). Some studies present strategies to couple the CFD models with BES software to obtain the values of CHTC and NWAT depending on the urban climate conditions (Yang et al., 2012).

However, the major problem of CFD models is the excessive computer burden in terms of both processing time and memory. As a consequence, it is very difficult to use CFD models coupled to BES tools to carry out annual simulations of buildings or building communities.

Recently, Mazuroski et al. (2018) proposed a strategy to explore the accuracy of BES-CFD coupling to simulate one full year by using an Artificial Neural Network (ANN) model, where a CFD model is used to simulate a convective phenomenon in an attic. With only few days simulated with the CFD model, the ANN model is capable to learn from data generated by the BES-CFD cosimulation and simulate the rest of the year with great level of accuracy and rapidness.

Therefore, the purpose of this paper is to propose a technique to simulate buildings located in towns considering the effect of the urban environment. Since the current BES tools do not normally deal with the urban effect, an intelligent co-simulation strategy inspired on Mazuroski et al. (2018) is proposed. First, a CFD model is coupled with a BES tool and the CHTC and NWAT values for each building wall is accurately computed for the first days of the simulation, while an ANN model is being trained with the simulation data. Then the CFD model is disconnected and the ANN performs the rest of the simulation, maintaining a great level of accuracy and demanding a significantly lower computational time. This methodology is applied on the BESTEST case considering a dense urban environment. The results show how significant the impact of the urban environment on CHTC, NWAT, outside surface temperature and indoor air temperature can be when a CFD model is employed in the simulation. Moreover, it is also shown that the ANN model, much faster to simulate, can keep a high level of accuracy, making viable the simulation of urban effects 
by current BES tools. The co-simulation is performed using DOMUS as BES tool and ANSYS-CFX as CFD model, by means of a Python script.

\section{Methods}

\section{CFD-BES Co-Simulation}

DOMUS is a building energy simulation tool developed to calculate energy and mass transfer, energy demand and thermal comfort in buildings (Mendes, Oliveira, and Santos, 2005). Recent developments have been introduced to improve direct solar radiative exchange simulation (Rocha, Oliveira, and Mendes, 2017). For the purpose of solving the problem investigated in this paper, DOMUS is coupled with the 3D-CFD ANSYS-CFX software (Ansys, 2006) to model velocity and temperature fields around the buildings and to compute the convective heat fluxes for each building wall. The coupling has been performed by a software (script) developed in Python language.

The first step to perform the coupling is to create the mock-up. After the definition of the buildings and grounds in DOMUS, the Python script extracts the geometrical data from DOMUS to build an urban canopy in the mesh-generator GMSH (Geuzaine and Remacle 2009). The urban canopy is represented as a wind tunnel centered on the area where the investigated buildings are located, respecting urban CFD simulation practices (Franke et al., 2007). After the mesh was created in GMSH, the python script exports the meshed model to ANSYS-CFX.

The next step of the coupling process is the execution of the simulation. For each time step, the Python script open DOMUS to simulate the next time step. At the end, each $T s_{i}$ (the outside surface temperature of the wall $i$ in the DOMUS geometry), is exported to ANSYS-CFX to define the boundary condition in the CFD simulation. The wind tunnel CFD boundary conditions are automatically determined according to the reference temperature $T_{\text {ref }}$, the reference wind speed $V_{\text {ref }}$ and the wind direction $D_{\text {ref }}$ from the weather file used in DOMUS simulation. The wind tunnel velocity profile boundary condition is determined as (Gandemer and Guyot, 1976):

$$
V(z)=\operatorname{Vref} *(z / \text { Zref })^{0.3}
$$

where $Z_{\text {ref }}$ is equal to $10 \mathrm{~m}$.

The turbulente kinetic energy $k$ and and the rate of dissipation of turbulence kinetic energy $\varepsilon$ at the wind tunnel boundary condition are defined according to Sini, Anquetin, and Mestayer (1996):

$$
\begin{gathered}
k=0.3 * \operatorname{Vref}^{2} \\
\varepsilon(z)=C_{\mu}{ }^{3 / 4} *\left(k^{3 / 2} / K_{m} z\right)
\end{gathered}
$$

where $C_{\mu}=0.009$ and $K_{m}=0.41$, represent the turbulent viscosity constant and the von Karman constants, respectively.

A steady RANS simulation with a k-Epsilon turbulence model is run with ANSYS-CFX to compute $\mathrm{CHTC}_{i}$ and $N W A T_{i}$ for each wall $i$. DOMUS is called one more time to simulate the same time step but considering the new values of $C H T C_{i}$ and $N W A T_{i}$. This iterative process between DOMUS and ANSYS-CFX, is repeated until the variation of $C H T C_{i}, N W A T_{i}$ and $T s_{i}$ between two consecutive iterations be lower than a pre-specified accuracy. In this particular experiment, only two iterations are needed to provide errors lower than $10^{-3}$. The coupling process is represented in Figure 1.

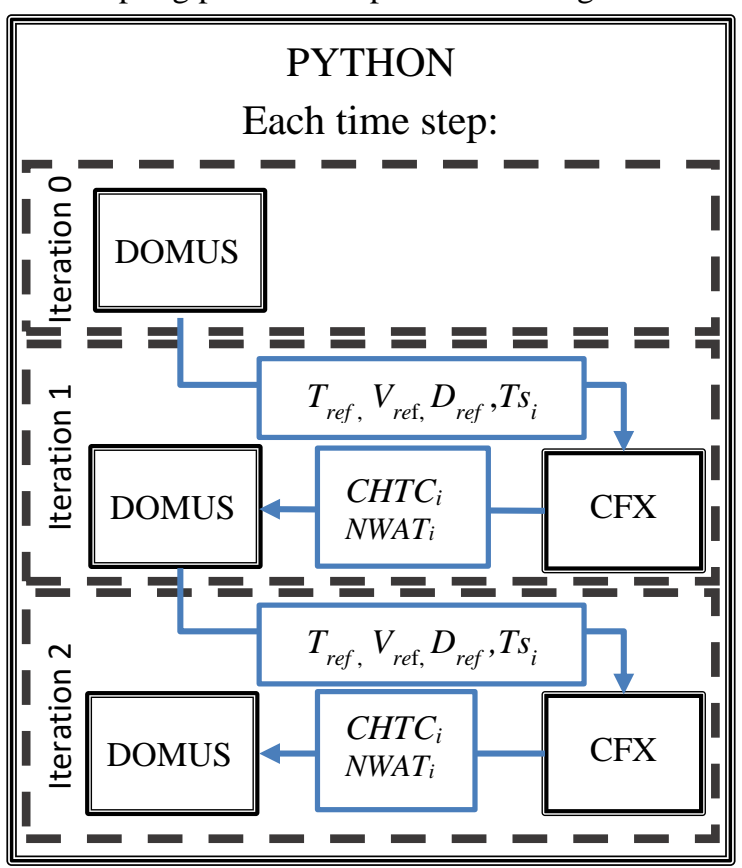

Figure 1: Representation of the coupling method between DOMUS and CFX.

\section{Intelligent co-simulation approach}

As expected, the computational time needed for CFD simulation is prohibitive for long simulation periods. Inspired on the approach presented by Mazuroski et al. (2018), we propose a methodology based on an artificial neural network (ANN) model, developed with the python library Keras using the Theano ANN model (Chollet, 2015). As in Mazuroski et al. (2018), the purpose of this ANN model is to replace the CFD model to compute $C H T C_{i}$ and $N W A T_{i}$ for each building wall after a short period of the simulation, reducing considerably the computational time of the whole simulation.

Basically, an ANN model is an interconnected group of nodes, based on the network structure of brain neurons. It is composed of three, or more layers (see the example in Figure 2). The first one is the input layer and the last one is the output layer. The intermediates layers are called hidden layers and are composed of several nodes named artificial neurons. For each node, $R_{n, m}$ (the value of the node $n$ of the layer $m$ ) is calculated in function of the values of the previous layer nodes according to the equation:

$$
R_{n, m}=\sum_{j=0}^{N_{m-1}} W_{j, \mathrm{~m}-1, \mathrm{n}, \mathrm{m}} R_{j, m-1}
$$

where $N_{m}$ is the number of nodes in the layer $m, W_{j, m-1, n, m}$ is the weight from the node $j$ of the layer $k$ to the node $n$ of the layer $m$. 


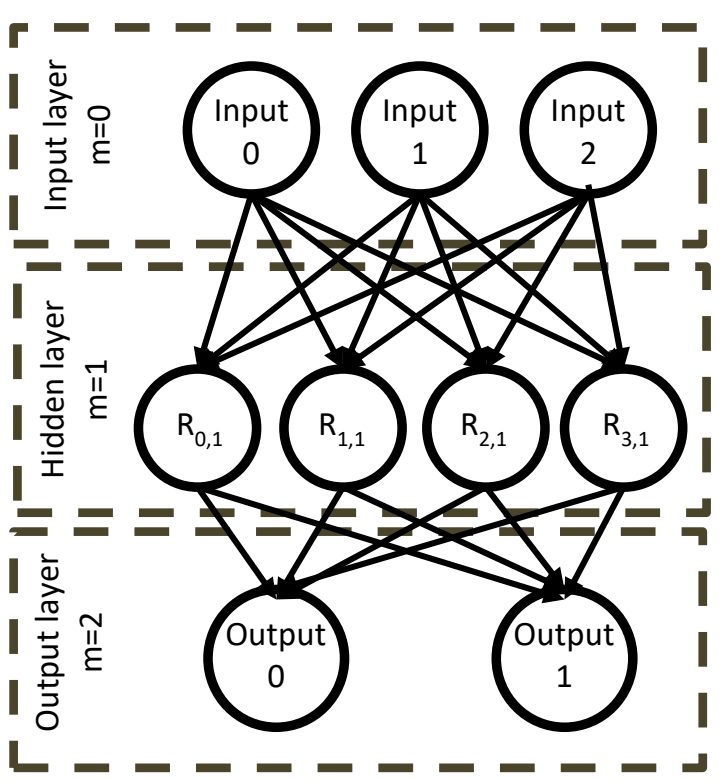

Figure 2: Example of an ANN with 3 inputs, 2 outputs and one hidden layer.

The weights of the ANN are computed during the phase named 'training phase' (Mazuroski et al., 2018), where the ANN model analyses a sample of data composed of inputs and outputs data to compute for each layer node, the weights allowing calculating output values corresponding to a set of inputs.

Once the weights are determined, the CFD can be disconnected from the coupling process and the ANN model can be used alone during the rest of the simulation period, also known as the 'Prediction phase' (Mazuroski et al., 2018).

For the present case study, two ANN models are built with regular neural network with a supervised learning. The first one is responsible to compute the CHTC values for each building wall and the second one to compute the NWAT for each building wall. The CHTC-ANN model is built with 3 inputs:

- $\quad$ reference temperature $T_{r e f}$,

- $\quad$ reference wind speed $V_{\text {ref }}$,

- $\quad$ wind direction $D_{\text {ref }}$

The CHTC-ANN model is composed of one hidden layer with four nodes. As outputs, it provides a vector of $N$ values containing the CHTC values for the $N$ building walls in contact with the outdoor environment.

The second ANN model computes the NWAT. It is composed of $N+3$ inputs:

- reference temperature $T_{\text {ref }}$,

- reference wind speed $V_{\text {ref }}$,

- wind direction $D_{\text {ref }}$,

- vector containing the $N$ outside surface temperature values.

This NWAT-ANN model is composed of one hidden layer with $N+4$ nodes and it provides as output a vector of $N$ values containing the NWAT for the $N$ building walls in contact with the outdoor.

To build both ANN models, the training phase uses the results from the coupled model DOMUS-CFX. For each time step, inputs are the values of $T s_{i}$ computed from DOMUS at the iteration 1 and the outputs are $C H T C_{i}$ and $N W A T_{i}$ values from CFX at the iteration 2.

After a short period of the simulation, the ANN models can be coupled with DOMUS to predict $C H T C_{i}$ and $N W A T_{i}$ values at each time step without using $\mathrm{CFX}$ as presented in Figure 3.

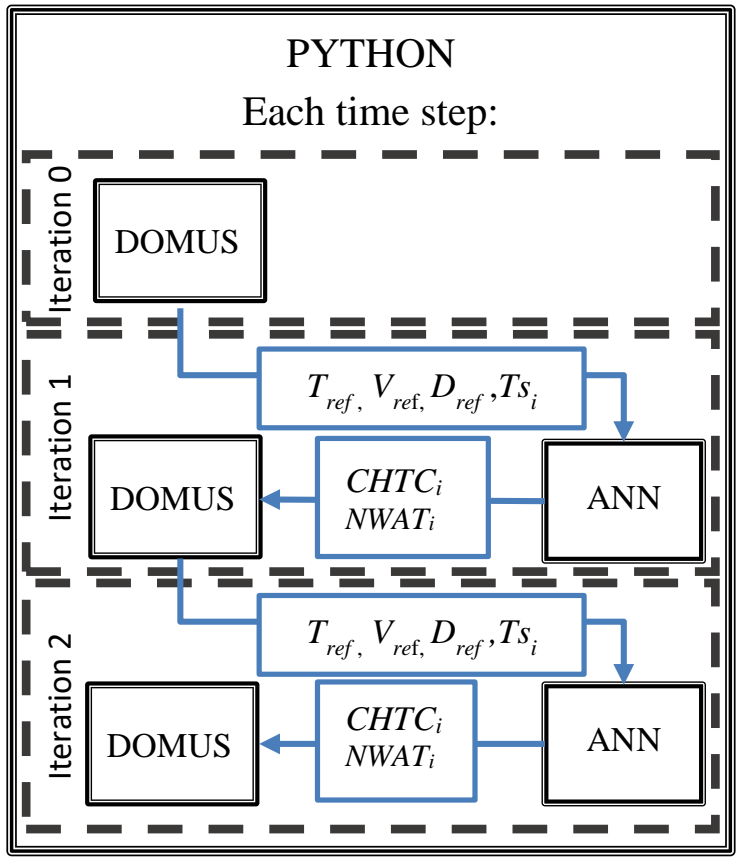

Figure 3: Representation of the coupling method between DOMUS and the ANN model.

Case study

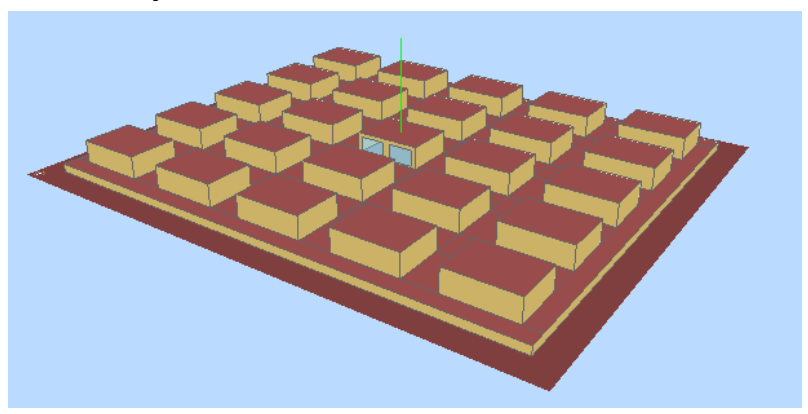

Figure 4: Three-dimensional representation of the BESTEST case in a dense urban environment.

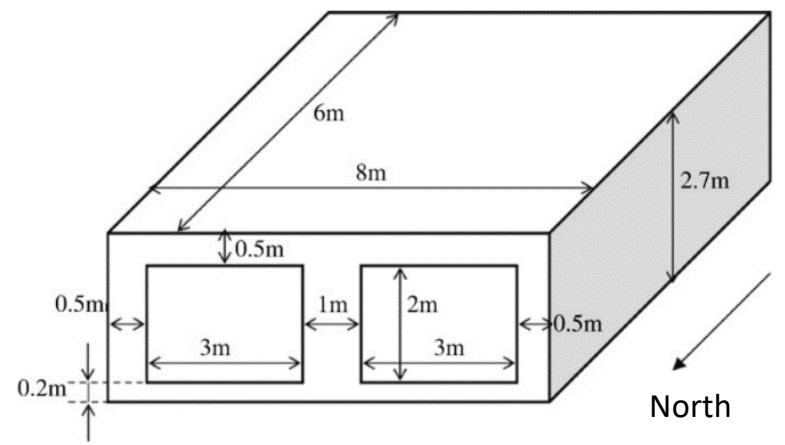

Figure 5 Three-dimensional representation of the BESTEST case (Judkoff and Neymark, 1995). 
The study case represents a dense urban space in the climate of Curitiba, PR, Brazil and it relies on the BESTEST geometry (Judkoff and Neymark, 1995). The urban geometry is represented by 25 buildings (see Figure 4). Each one has the same dimensions than the 600 BESTEST case (Henninger and Witte, 2004) as represented in Figure 5. Only the central building has windows as described in the 600 BESTEST case, but north oriented. The distance among buildings is $4 \mathrm{~m}$ corresponding to a canyon street aspect ratio (building high/street width) of 0.675 and a skimming regime flow (Oke, 1988).

The materials of ground and buildings walls used in this case are summarized in Table 1. The thermophysical properties of the different materials are provided in the Table 2.

Table 1: Materials used in the simulation case.

\begin{tabular}{|c|c|c|c|}
\hline Location & $\begin{array}{c}\text { Roofs and } \\
\text { buildings wall }\end{array}$ & Street & windows \\
\hline Composition & $\begin{array}{c}\text { plaster/brick/ } \\
\text { plaster }\end{array}$ & $\begin{array}{c}\text { concrete } \\
\text { / ground }\end{array}$ & glazing \\
\hline Thickness[cm] & $2 / 15 /$ & $20 /$ & 0.3 \\
2 & 0.8 & 0.8 & 0.1 \\
\hline $\begin{array}{c}\text { Solar } \\
\text { absorptivity }\end{array}$ & 0.9 & 0.9 & 0.84 \\
\hline Emissivity & 0.9 & \\
\hline
\end{tabular}

Table 2: Thermophysical properties of the materials.

\begin{tabular}{|c|c|c|c|}
\hline Material name & $\begin{array}{c}\text { Density } \\
{\left[\mathbf{k g} / \mathbf{m}^{\mathbf{3}}\right]}\end{array}$ & $\begin{array}{c}\text { Thermal } \\
\text { conductivity } \\
{[\mathbf{W} / \mathbf{m} \mathbf{2 K}]}\end{array}$ & $\begin{array}{c}\text { Thermal } \\
\text { mass } \\
{[\mathbf{J} / \mathbf{k g ~ K}]}\end{array}$ \\
\hline plaster & 2050 & 0.720 & 932 \\
\hline brick & 1900 & 0.749 & 920 \\
\hline concrete & 2200 & 1.75 & 1000 \\
\hline ground & 2050 & 0.520 & 840 \\
\hline glazing & 2200 & 1 & 750 \\
\hline
\end{tabular}

The urban canopy is built respecting urban CFD simulation practices (Franke et al., 2007) for any wind direction considering the central building. Then, the wind tunnel height is 6 times higher than the central building height (16,2 meters), and the distance from the central building to the wind tunnel limits is greater than 15 times the central building height (see Figure 6).

A tetrahedral mesh was used with different mesh size (see Figure 6). The central building mesh size is $0.25 \mathrm{~m}$. For the other buildings, the mesh size is $0.5 \mathrm{~m}$ and for the limit of wind tunnel, the mesh size is $5.5 \mathrm{~m}$. As a consequence, the total number of elements is 64404. These different mesh sizes were chosen to respect Yplus values ranging between 10 and 200 .

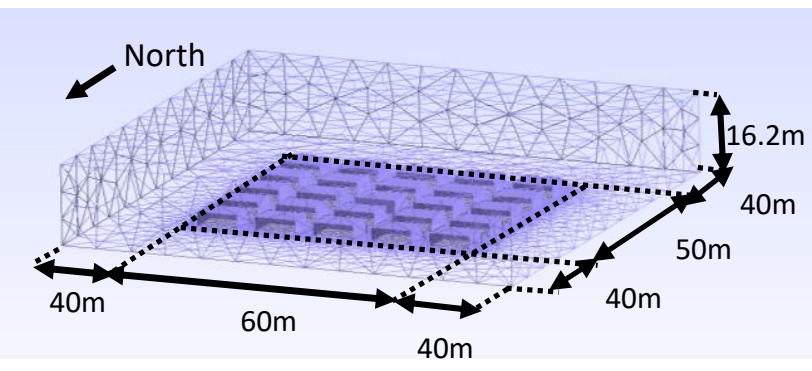

Figure 6: Three-dimensional representation of the mesh used to model the urban canopy around the buildings.

\section{Results}

\section{BES-CFD Co-simulation}

A co-simulation between DOMUS and ANSYS-CFX was run from January $9^{\text {th }}$ to January $16^{\text {th }}$ using the weather data of Curitiba, Brazil. The coupling process needs four more days to simulate one week with 2 iterative process between DOMUS and ANSYS-CFX. Indeed, after two iteration processes between DOMUS and ANSYS-CFX, the relative difference of the outside surface temperature, NWAT and CHTC results are lower than $10^{-3}$.

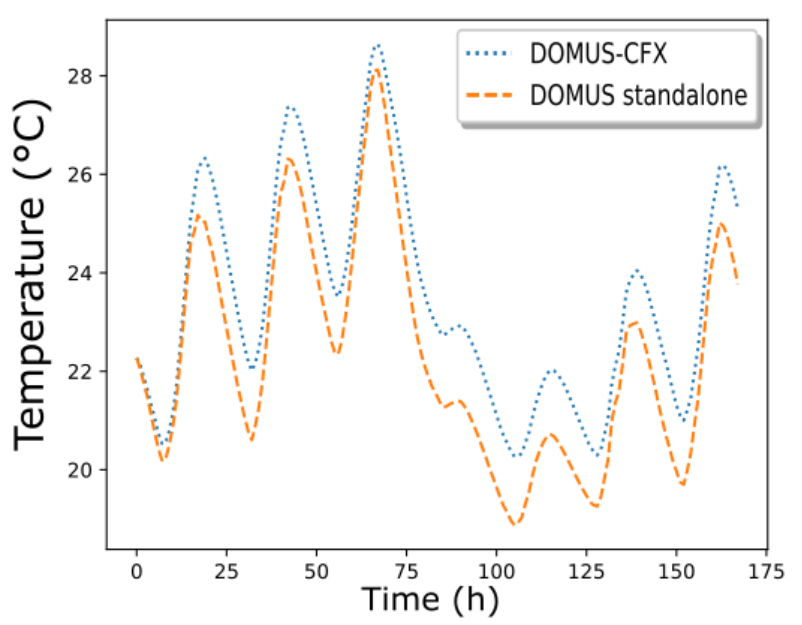

Figure 7: Indoor air temperature computed with DOMUS-CFX and DOMUS standalone.

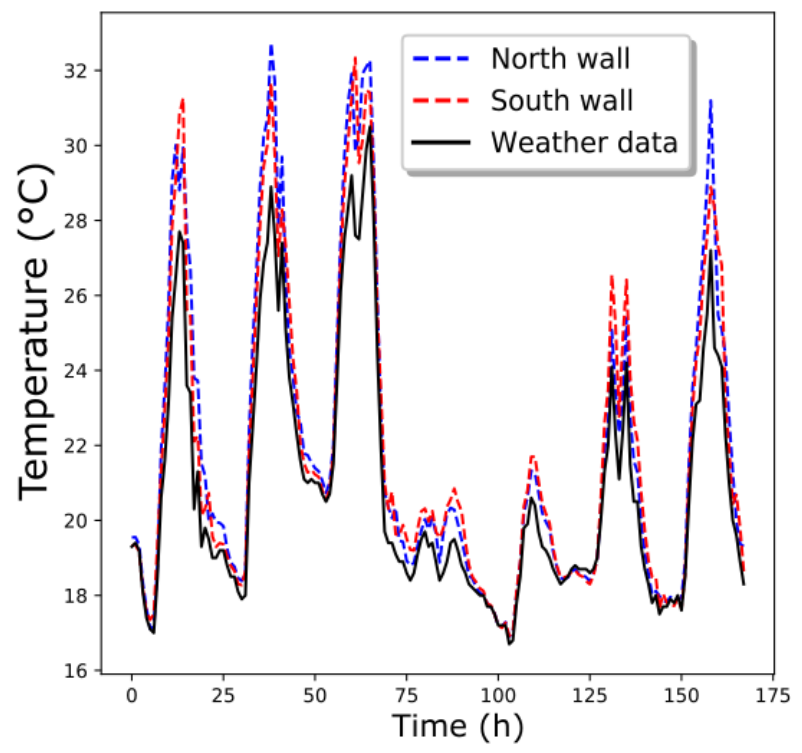

Figure 8: Near Wall Air Temperature computed with DOMUS-CFX

The results show the impact of the urban environment on outside surface temperatures, NWAT and CHTC values for each wall, and for the indoor air temperature of the central building.

The comparison between DOMUS standalone and with DOMUS-CFX results (the coupling between DOMUS and ANSYS-CFX), highlights the impact of urban environment on simulation results. In this case, urban environment in BES increases: 
- indoor air temperature between $0.5^{\circ} \mathrm{C}$ and $1.5^{\circ} \mathrm{C}$ (see Figure 7).

- $\quad$ NWAT until $4^{\circ} \mathrm{C}$ (see Figure 8).

- outside surface temperature until $6^{\circ} \mathrm{C}$ (see Figure 9). Futhermore, the difference between the CHTC values used in the DOMUS standalone version and the DOMUSCFX coupling method can exceed $11 \mathrm{~W} / \mathrm{m}^{2}-\mathrm{K}$ (see Figure $10)$.

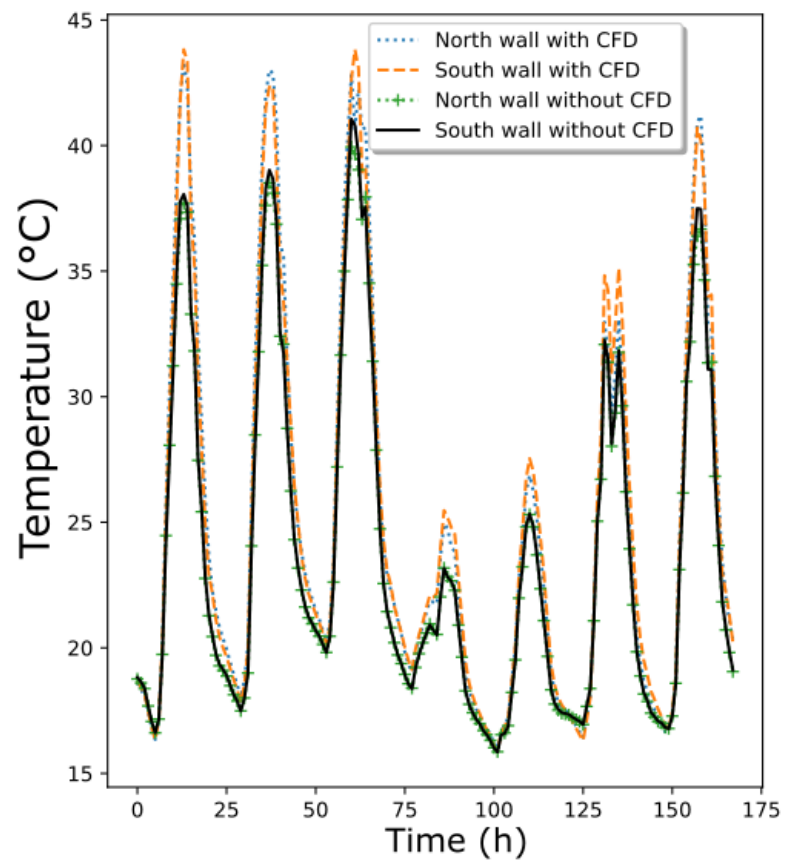

Figure 9: Surface temperature computed with DOMUSCFX.

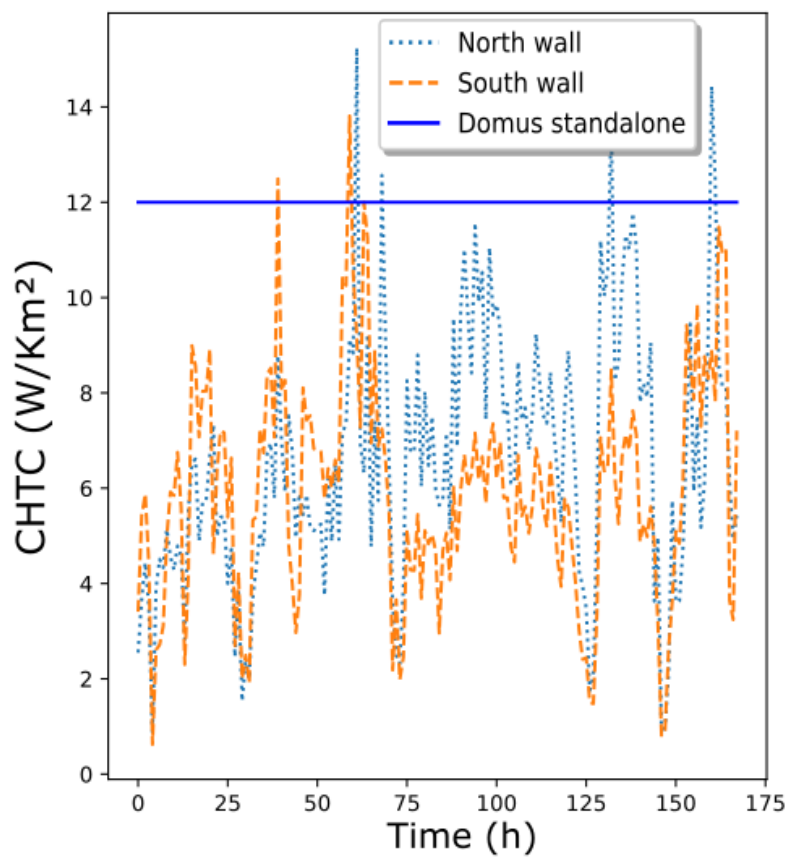

Figure 10: Convective Heat Transfer Coefficient computed with DOMUS-CFX.

The use of the DOMUS-CFX coupling method, not only provides CHTC and NWAT results different from DOMUS standalone version, but also allows to obtain significant differences among the buildings walls. For example, between the north and the south walls, differences are higher than:

- $\quad 2{ }^{\circ} \mathrm{C}$ for the NWAT (see Figure 8).

- $6 \mathrm{~W} / \mathrm{m}^{2} \mathrm{~K}$ for the CHTC (see Figure 10).

As the NWAT depends on the wind speed and direction, it may be noted that it is not always the sunniest wall (north wall) that has the higher NWAT values (see Figure 8 ). Indeed, temperature fields are highly affected by the local microclimate condition.

\section{ANN results}

As explained before, the DOMUS-CFX co-simulation results are used to build the ANN models. The inputs ( $T_{r e f}$, $V_{\text {ref, }} D_{\text {ref }}$ and $\left.T s_{i}\right)$ and outputs $\left(C H T C_{i}\right.$ and $\left.N W A T_{i}\right)$ of CFX at the second iteration (see Figure 1) are used to train the ANN models. Few minutes are needed to train the ANN models.

After that, the ANN models is used to predict $C H T C_{i}$ and $N W A T_{i}$ values using CFX inputs ( $T_{r e f,}, V_{\text {ref, }} D_{\text {ref }}$ and $T s_{i}$ ) of the second iteration of each time step of DOMUS-CFX simulation. In this way, the ANN models are not coupled with DOMUS. The time needed to predict all $N W A T_{i}$ and CHTC $i$ values are around $10^{-1}$ seconds.

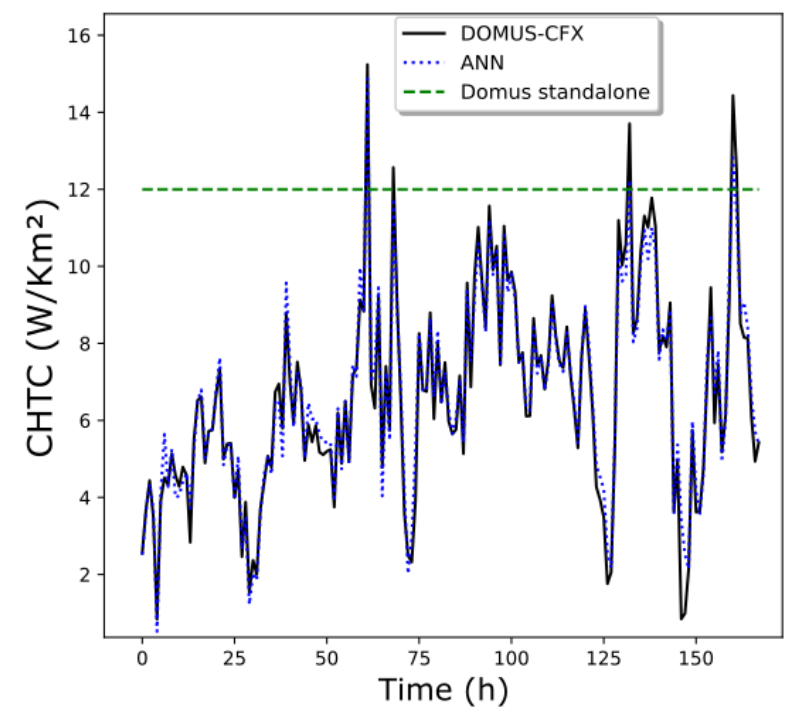

Figure 11: CHTC computed with DOMUS-CFX, the ANN model and DOMUS standalone for the North wall of the central building.

Figure 11 and Figure 12 show respectively the values CHTC and NWAT for the north wall with three different methods:

- DOMUS-CFX results after the second iteration.

- ANN predicted results using CFX inputs of the second iteration of DOMUS-CFX results.

- DOMUS standalone results considering the weather data.

In this way, as the DOMUS outputs are independent of the ANN predicted values, the ANN models are not coupled with DOMUS. Comparing the results with DOMUS-CFX allows analysing the precision of the ANN models. The accuracy of the ANN models corresponds to:

- A maximum error of $2.5 \mathrm{~W} / \mathrm{m}^{2} \mathrm{~K}$ for the CHTC values.

- A maximum error of $1.2^{\circ} \mathrm{C}$ for the NWAT. 
Even though the difference between the CFD model and the ANN models are relatively high, ANN models can predict much better the impact of the urban environment than the BES standalone simulation tool.

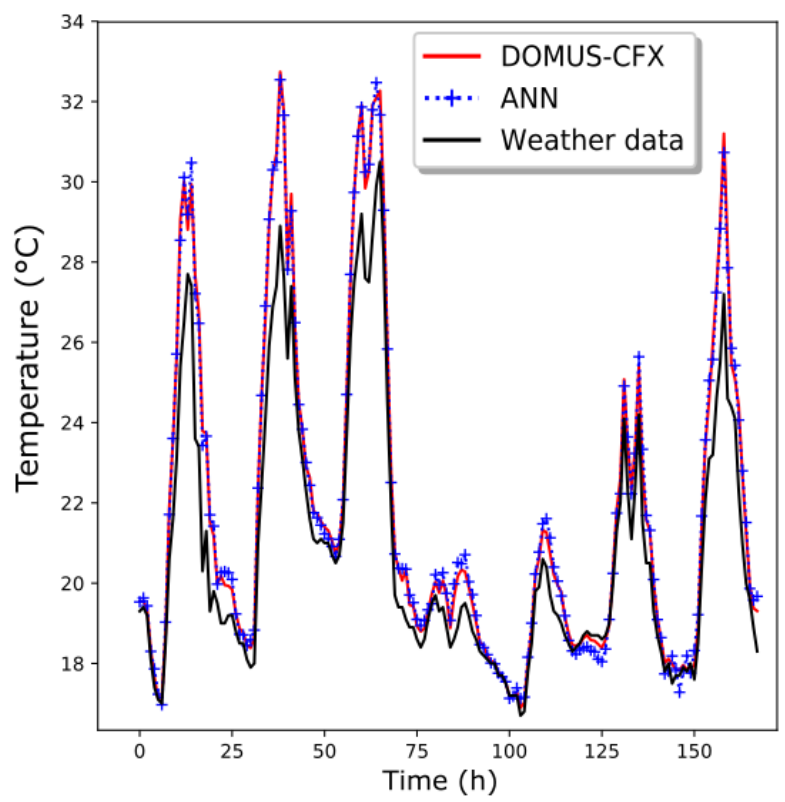

Figure 12: NWAT computed with DOMUS-CFX, the ANN model and DOMUS standalone for the North wall of the central building.

\section{ANN-BES Co-Simulation}

The ANN models trained with DOMUS-CFX cosimulation results from $9^{\text {th }}$ to $16^{\text {th }}$ of January are coupled with DOMUS to run a simulation for the next week (from $17^{\text {th }}$ to $24^{\text {th }}$ of January). At each time step, the ANN models predict $N W A T_{i}$ and $C H T C_{i}$, and DOMUS uses these values to model the indoor temperature and the $T s_{i}$. In this case, two iterative processes are used to couple DOMUS with the ANN models, as presented in Figure 3. The computer run time needed to model one week is of the order of 7 hours.

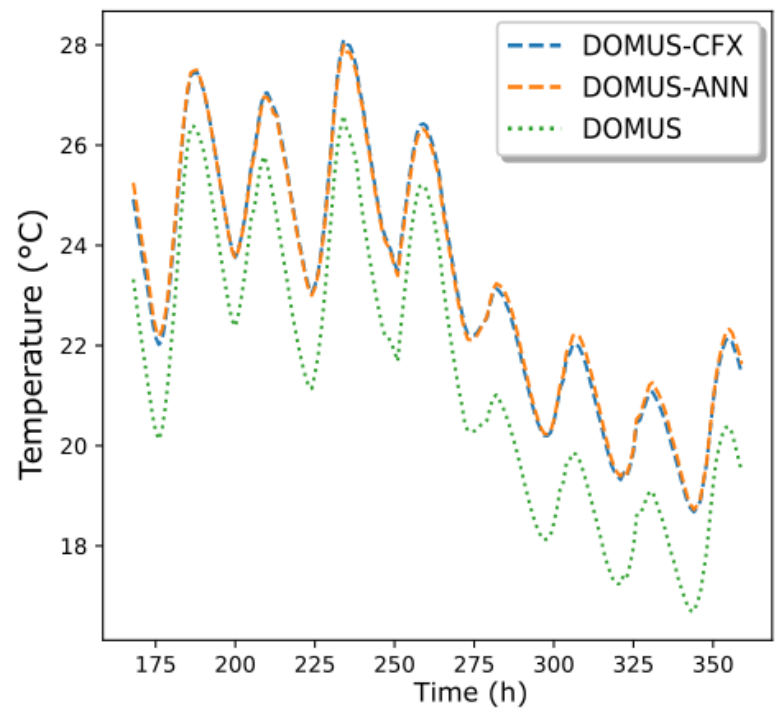

Figure 13: Indoor air temperature computed with DOMUS-CFX, DOMUS-ANN and DOMUS standalone.

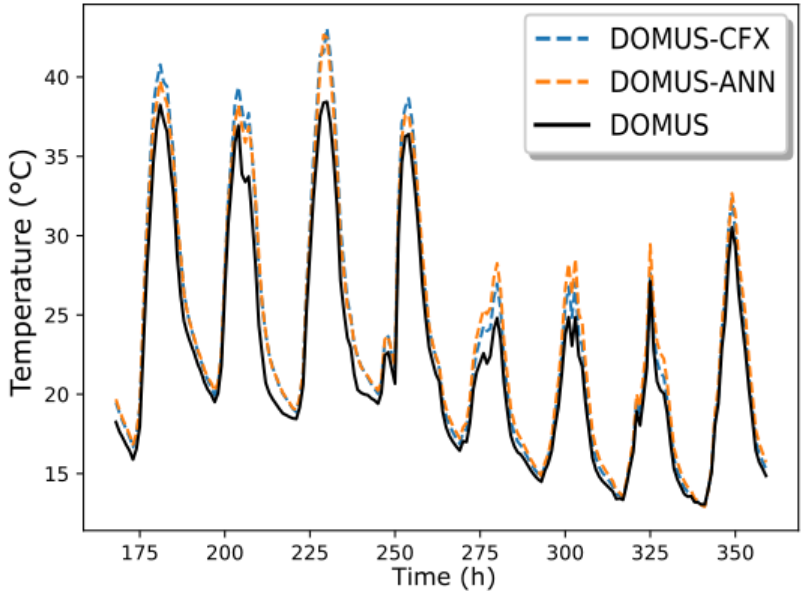

Figure 14: North wall surface temperature computed with DOMUS-CFX, DOMUS-ANN and DOMUS standalone.

Figure 13 and Figure 14 present respectively results of indoor air temperature of the central zone and outside temperature of the north wall. At each time step, the results of DOMUS-ANN (coupling between DOMUS and the ANN model) are compared with DOMUS-CFX results and DOMUS standalone simulation.

We can note that in this comparison, the CFX input data and those for the ANN-based models are not exactly the same. Indeed, during the coupling process the inputs of CFX (or the ANN models) are dependent of DOMUS outputs $\left(T s_{i}\right)$ that were calculated by using $C H T C_{i}$ and $N W A T_{i}$ values computed with CFX (or the ANN models). The lack of precision of the ANN models, compared to CFX, leads to error accumulation at each time step. Nevertheless, the difference between DOMUS-CFX and DOMUS ANN does not exceed:

- $0.35^{\circ} \mathrm{C}$ for the indoor temperature

- $1.75^{\circ} \mathrm{C}$ for the northwall outside surface temperature. Once again, even though the differences between the DOMUS-CFX and DOMUS-ANN coupling method are relatively high (error higher than $1 \%$ for the indoor air temperature and $5 \%$ for the outside surface temperature), the accuracy is much better than using a standalone BES software to represent the impact of the urban environment.

\section{Conclusion}

We presented in this paper a co-simulation strategy between a BES tool and a CFD model to take into account the urban environment impact on outdoor convective fluxes that are considered by the BES software.

Basically, first the BES-CFD coupling is performed normally for a short period of simulation, in general requiring a great computational effort. Then, ANN models are trained using the input and output data of the BES-CFD co-simulation. Finally, the CFD is disconnected and the ANN models are coupled with a BES model to perform the rest of the simulation.

The BES-CFD co-simulation needs four days to simulate one week while the BES-ANN co-simulation needs only seven hours to simulate the same time period. Compared 
to the CFD model, the accuracy of the ANN model is within the range of $95 \%$.

However, as the coupling method between DOMUS and the ANN models is not integrated into DOMUS, the calculation time is still too high. Indeed, this coupling process is controlled by Python (see Figure 3), that needs to open and close DOMUS at each time step (a timeconsuming procedure). Improvements in this direction (for instance, encapsulating the Python script in a FMI standard ('Functional Mock-up Interface' n.d.) would certainly reduce the calculation time, making feasible the simulation of one year in a few minutes.

The DOMUS-ANN coupling method shows promising perspectives to model urban microclimate and its impact on building performance. However, to build an ANN model able to simulate the full year condition, we need to simulate in advance with the CFD model a set of conditions to allow the ANN to learn how to simulate all the possible conditions during the year. Then, the future challenge of this work is to develop a methodology to define what situation must be performed with the CFD model, to build an ANN model able to predict the conditions all year long. One the other hand, other artificial neural network type, as the Recurrent Neural Network, will be tested to improve the accuracy of ANN based-models.

To conclude, an ANN model to replace an urban microclimate CFD simulation can be very promising. Indeed, the advantage of using the ANN model to predict only the outdoor NWAT and CHTC values (and not the indoor air temperature and outside surface temperature), is that this model is independent of BES parameters. When the geometry is defined in the BES software, it is possible to test different types of materials, colours, wall types, and HVAC systems with the same ANN model without the need of producing new CFD training simulation.

\section{Acknowledgments}

The authors also acklowledge the French and Brazilian agencies for their financial supports through the project CAPES--COFECUB, as well as the CNPQ of the Brazilian Ministry of Education and of the Ministry of Science, Technology and Innovation, respectively, for cofunding.

\section{References}

Ansys, C. F. X. 2006. 'ANSYS CFX'. Academic Research Release 11.

Bouyer, J., C. Inard, and M. Musy. (2011). Microclimatic Coupling as a Solution to Improve Building Energy Simulation in an Urban Context. Energy and Buildings 43, 1549-1559.

Chollet, F. 2015. 'Keras'. GitHub Repository.

Emmel, M. G., M. O. Abadie, and N. Mendes. (2007). New External Convective Heat Transfer Coefficient Correlations for Isolated Low-Rise Buildings. Energy and Buildings 39, 335-342.

Franke, J., A. Hellsten, H. Schlünzen, and B. Carissimo. (2007). Best Practice Guideline for the CFD
Simulation of Flows in the Urban Environment. Cost Action 732.

Freire, R., Z., G. H. C. Oliveira, and N, Mendes. (2008). Development of Regression Equations for Predicting Energy and Hygrothermal Performance of Buildings. Energy and Buildings 40,810-820.

'Functional Mock-up Interface'. n.d. Accessed 2 January (2019). https://fmi-standard.org/.

Gandemer, J., and A Guyot. (1976). Intégration du phénomène vent dans la conception du milieu bâti: guide méthodologique et conseils pratiques. Paris (France): Ministère de l'équipement, Direction de l'aménagement foncier et de l'urbanisme: Diffusion, La documentation française.

Geuzaine, C., and J. F. Remacle. (2009). Gmsh: A 3-D Finite Element Mesh Generator with Built-in Pre-and Post-Processing Facilities'. International Journal for Numerical Methods in Engineering 79, 1309-1331.

Henninger, R. H., and M. J. Witte. (2004). EnergyPlus Testing with ANSI/ASHRAE Standard 1402001 (BESTEST) EnergyPlus Version 1.2. 1.012. Lawrence Berkeley National Laboratory, Berkeley, California.

Judkoff, R., and J. Neymark. (1995). International Energy Agency Building Energy Simulation Test (BESTEST) and Diagnostic Method. National Renewable Energy Lab., Golden, CO (US).

Mazuroski, W., J. Berger, R. C. L. F. Oliveira, and N. Mendes. (2018). An Artificial IntelligenceBased Method to Efficiently Bring CFD to Building Simulation. Journal of Building Performance Simulation 11,588-603.

Mendes, N., R.C.L.F. Oliveira, and G. H. Santos. (2005). Energy Efficiency and Thermal Comfort Analysis Using the Powerdomus Hygrothermal Simulation Tool. In Proc. of the Nineth Building Simulation Conference (IBPSA'05). Montreal (Canada), 15-18 August 2005.

Merlier, L., F. Kuznik, G. Rusaouën, and J. Hans. (2015). An Adapted Steady RANS RSM Wall-Function for Building External Convection. Building and Environment 94, 654-664.

Morille, B., N. Lauzet, and M. Musy. (2015). SOLENEMicroclimate: A Tool to Evaluate Envelopes Efficiency on Energy Consumption at District Scale. Energy Procedia, 6th International Building Physics Conference, IBPC 2015. Torino (Italy), 14-17 June 2015.

Oke, T. R. (1988). Street Design and Urban Canopy Layer Climate. Energy and Buildings 11, 103-13.

Rocha, A. P. A., R. C. L. F. Oliveira, and N. Mendes. (2017). 'Experimental Validation and Comparison of Direct Solar Shading Calculations within Building Energy Simulation Tools: Polygon Clipping and Pixel Counting Techniques. Solar Energy 158 (Supplement C), 462-73. 
Sini, J.-F., S. Anquetin, and P.G. Mestayer. (1996). 'Pollutant Dispersion and Thermal Effects in Urban Street Canyons'. Atmospheric Environment 30, 2659-77.

Toparlar, Y., B. Blocken, P. Vos, G. J. F. van Heijst, W. D. Janssen, T. van Hooff, H. Montazeri, and H. J. P. Timmermans. (2015). CFD Simulation and Validation of Urban Microclimate: A Case Study for Bergpolder Zuid, Rotterdam'. Building and Environment, Special Issue: Climate adaptation in cities, 83, 79-90.
Wang, X., and Y. Li. (2016). Predicting Urban Heat Island Circulation Using CF'. Building and Environment 99, 82-97.

Yang, X., L. Zhao, M. Bruse, and Q. Meng. (2012).An Integrated Simulation Method for Building Energy Performance Assessment in Urban Environments. Energy and Buildings 54,243251. 